\title{
Regional Employment and Occupational Morbidity Indicators in Western Kazakhstan
}

\author{
Zhangeldy Shaimbetov ${ }^{1}$, Umit Satybaldieva ${ }^{1,2 *}$, Arstan Mamyrbayev $^{1}$ \\ ${ }^{1}$ Department of Hygienic Disciplines and Professional Diseases, West Kazakhstan Marat Ospanov State Medical University, \\ Aktobe, Kazakhstan, Asia; ${ }^{2}$ Western Kazakhstan Branch of RSE for REM National Center of Examination of the Committee of \\ Protection of Public Health of the Ministry of Health of RK, Aktobe, Kazakhstan, Asia
}

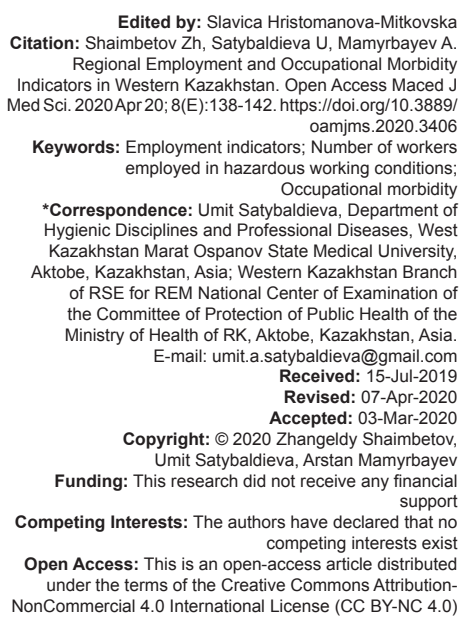

Edited by: Slavica Hristomanova-Mitkovska Citation: Shaimbetov Zh, Satybaldieva U, Mamyrbayev A. Regional Employment and Occupational Morbidity Indicators in Western Kazakhstan. Open Access Maced J
Med Sci. 2020 Apr 20;8(E):138-142. https://doi.org/10.3889/ Med Sci. 2020Apr 20; 8(E):138-142. https://doi.org/10.3889 Keywords: Employment indicators; Number of workers employed in hazardous working conditions: *Correspondence: Umit Satybaldieva, Department of Hygienic Disciplines and Professional Diseases, Wes Kazakhstan Marat Ospanov State Medical University, Aktobe, Kazakhstan, Asia; Western Kazakhstan Branch of RSE for REM National Center of Examination of the Committee of Protection of Public Health of the Health of RK, Aktobe, Kazakhstan, Asia. Received: 15-Jul-2019 Revised: 07-Apr-2020 Accepted: 03-Mar-2020 Copyright: ๑ 2020 Zhangeldy Shaimbetov, Copyright: @ 2020 Zhangeldy Shaimbetov, Funding: This research did not receive any financia Competing Interests: The authors have declared that no competing interests exis Open Access: This is an open-access article distribute under the terms of the Creative Commons Attribution-
nCommercial 4.0 International License (CC BY-NC 4.0)

\begin{abstract}
BACKGROUND: The article deals with regional employment and occupational morbidity indicators in Western Kazakhstan

AIM: The purpose is to study the employment indicators in hazardous working conditions and the dynamics of occupational morbidity in the West Kazakhstan region for the period 2013-2017.

MATERIAL AND METHODS: Materials obtained from the Public Health Departments of the Aktobe, Atyrau, West Kazakhstan, and Mangystau regions were studied based on the results of periodic medical examinations of workers employed in hazardous working conditions for the period 2013-2017. The indicators of the dynamics of occupational morbidity in the region are derived from the annual reports of the West Kazakhstan branch of the RSE at the National Hygiene Center for Occupation and Occupational Diseases of the Ministry of Healthcare of the Republic of Kazakhstan for the period 2013-2017.
\end{abstract}

RESULTS: The Atyrau, West Kazakhstan, and Mangystau regions saw an annual increase in the number of workers employed in hazardous production. In the Aktobe region, the number of people employed in hazardous working conditions decreased due to the decline in industrial production. There is a positive trend in this region to identify occupational diseases. In the Atyrau, West Kazakhstan, and Mangystau regions, the occupational morbidity rate is close to zero.

CONCLUSION: It is necessary to revise the existing orders of the Ministry of Healthcare of the Republic of Kazakhstan concerning the improvement of the occupational health service.

\section{Introduction}

The quality of the country's labor resources is determined by the number of workers and their level of health. The main indicator of the health of the working population and the most important criterion for assessing occupational risk in the workplace is occupational morbidity [1], [2], [3].

The Occupational Health and Safety Program of the Republic of Kazakhstan approved by the Decree of the Government of the Republic of Kazakhstan No. 67 as of January 27, 2005, provides specific information about the non-compliance of the working conditions of industrial enterprises with hygienic standards for dust, chemicals, and physical factors. It is noted that the depreciation of fixed assets is more than $50 \%$ [4]. Long-term hygienic studies, conducted by Kazakhstani scientists in the framework of planned research and development work, as well as certification audit of the working conditions of production facilities show that $80 \%$ of industrial enterprises of the Republic of Kazakhstan do not meet sanitary and hygienic standards for production and environment [5]. It has been established that more than two thousand industrial enterprises are environmental pollutants, which annually contribute to the entry of tens of millions of tons of harmful impurities into the air [6].

An analysis of various sources revealed a worsening of the demographic situation in the industrial regions of Western Kazakhstan, as well as an increase in the overall incidence rate and malignant tumors [7], [8], [9]. For example, in the Aktobe region, the mortality rate of the population in the area of the chromium biogeochemical industry is $11.8 \%$ above the regional average and $11 \%$ above the republican average, and there is an increase in the level of disability [10].

According to the Committee on Statistics of the Republic of Kazakhstan, the actual number of workers employed in hazardous working conditions in the country is 368.8 thousand people, one-third of whom work in Western Kazakhstan's enterprises [11]. The recent special literature is replete with the results of hygienic and medico-ecological studies, according to which the technological processes of open and 
underground chrome ore mining at the Don Ore Mining and Processing Plant (Khromtau) as well as ferroalloy and chrome production correspond to class $3.1-3.3$ in terms of the degree of hazard, severity, and intensity of labor. The main harmful factors are adverse microclimatic conditions, gas pollution and dustiness of the working area, and high levels of noise and vibration, as well as heavy hard labor [12], [13], [14]. In addition, the region has the world's largest developed oil and gas fields - Tengiz, Karachaganak, and Kashagan. The region is the main base of the country's hydrocarbon raw materials (oil, gas, and gas condensate), the negative factors of which affect the formation of public health [15], [16], [17].

The purpose of the present study is to analyze the employment indicators in hazardous working conditions and the dynamics of occupational morbidity in the West Kazakhstan region over the period from 2013 to 2017.

\section{Materials and Methods}

Materials obtained from the Public Health Departments of the Aktobe, Atyrau, West Kazakhstan, and Mangystau regions were studied based on the results of periodic medical examinations of workers employed in hazardous working conditions for the period 2013-2017. The indicators of the dynamics of occupational morbidity in the region are derived from the annual reports of the West Kazakhstan branch of the RSE at the National Hygiene Center for Occupation and Occupational Diseases of the Ministry of Healthcare of the Republic of Kazakhstan for the period 2013-2017.

A trend analysis of the data was carried out using the Statistica-10 program by the least-squares method with the calculation of growth rates.

\section{Results}

The employment rates of the able-bodied population in the Aktobe region from 2013 to 2017 are characterized by an annual decline. Its rate amounted to $6.42 \%$. On the contrary, in other areas of the Western region, for the same period, there is a positive trend in the number of workers. The average annual increase in the number of workers in production in the Atyrau, West Kazakhstan, and Mangystau regions for 2013-2017 was $11.54 \%, 10 \%$, and $6.5 \%$, respectively (Figure 1).

An analysis of employment indicators in hazardous working conditions showed that in the Aktobe region, the share of workers employed in industries

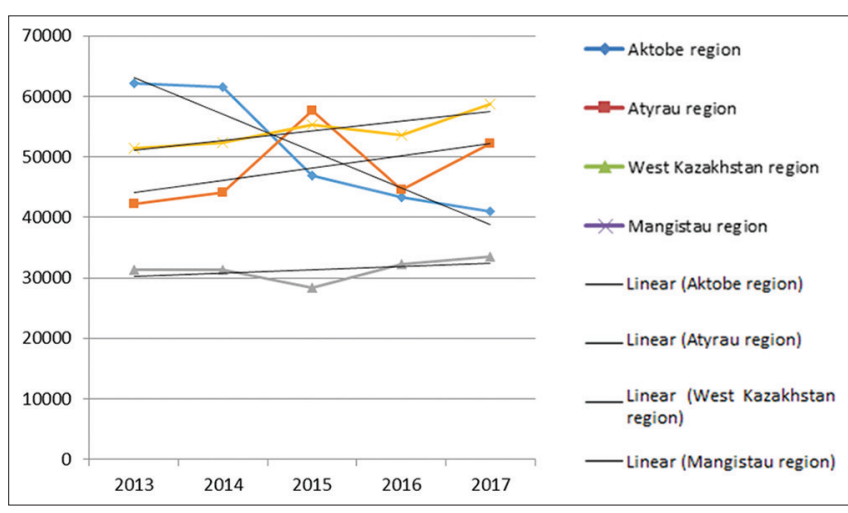

Figure 1: Dynamics of employment rates in Western Kazakhstan

with hazardous working conditions amounted to $82.8 \%$ of the total number of workers in 2013. In dynamics, this indicator was decreased in the following years, reaching $82.6 \%$ in $2014,84.2 \%$ in $2015,80.2 \%$ in 2016 , and $59.1 \%$ in 2017 .

The employment indicators of workers in hazardous working conditions in the Atyrau region for the analyzed period are characterized by instability. For example, in 2013, this figure was $60.1 \%$. In 2014 and 2015 , there was a decrease to $57.8 \%$ and $58.1 \%$, respectively. In subsequent years, there was a sharp increase in the indicator to $83.2 \%$ in 2016 and to $87.5 \%$ in 2017.

In the West Kazakhstan region, from 2013 to 2015 , there was a tendency to a decrease in the number of workers employed in industries with hazardous working conditions. In subsequent years, there was a significant increase in this indicator, and by the end of 2017 , it amounted to $61.8 \%$ of the total number of workers.

In the Mangystau region, in 2013, 2014, and 2015 , the number of workers employed in hazardous industries was relatively stable, accounting for $61.01 \%$, $61.57 \%$, and $61.89 \%$ of the total number of workers, respectively. In 2016, there was no significant increase in the number of workers employed in hazardous working conditions. However, due to the general decline in employment rates, the number of people employed in hazardous working conditions began to account for $70.85 \%$ of the total number of workers. In 2017 , there was an increase in the number of workers employed in hazardous working conditions $(78.35 \%)$ and in the total number of workers in the Mangystau region (Figure 2).

When comparing the dynamics of primary occupational morbidity in the Western region with the average dataforKazakhstan[18], [19], Russia[20], [21], [22] and some developed industrial countries [23], [24], [25], a generally low level of occupational morbidity was revealed. At the same time, only the Aktobe region is characterized by a tendency to an increase in the occupational morbidity rate, which amounted to $0.58,0.78,0.75,0.86$, and 1.03 in 2013, 2014, 2015, 2016, and 2017, respectively. In particular years, isolated cases of primary occupational 


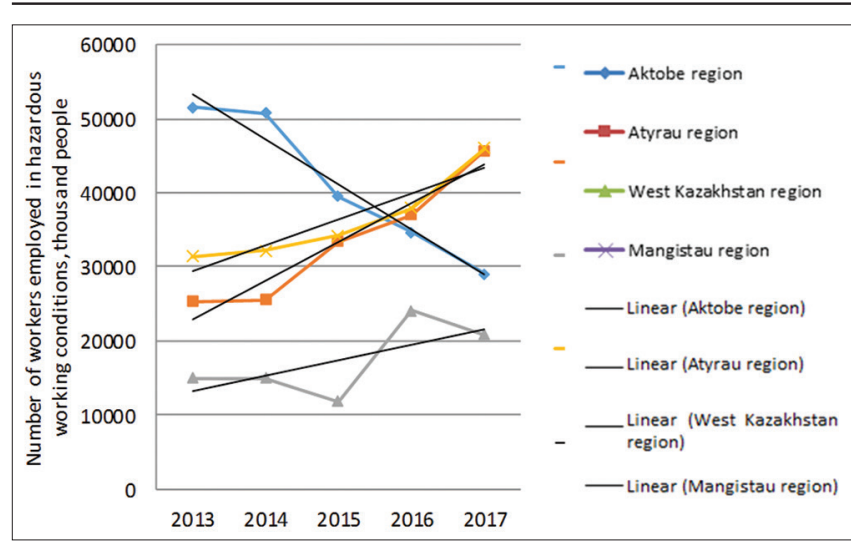

Figure 2: Dynamics of employment indicators in hazardous working conditions in Western Kazakhstan

diseases are observed in the Atyrau and Mangystau regions. However, in general, the occupational morbidity rate in these areas is close to zero. Over the past 5 years, no cases of occupational diseases have been identified in the West Kazakhstan region (Figure 3).

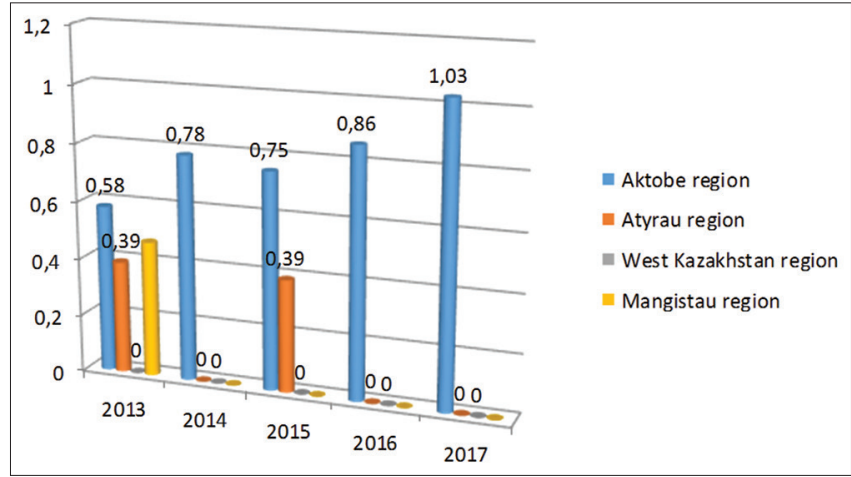

Figure 3: Dynamics of occupational morbidity indicators in Western Kazakhstan (per 10,000 workers)

\section{Discussion}

The implementation of a number of state programs aimed at strengthening the economy and socioeconomic transformations in the Republic of Kazakhstan contributed to the creation of a dynamically developing labor market [26]. According to the Committee on Statistics of the Republic of Kazakhstan, in the post-crisis conditions of the global economy, the situation in the whole country in terms of employment and unemployment is stable. As shown by our studies, in the Atyrau, West Kazakhstan, and Mangystau regions, there was an annual increase in the number of people employed in production. A different picture was observed in the Aktobe region, where in 2015, seven large industrial facilities shut down, which negatively affected both the total working population and the proportion of workers employed in hazardous working conditions.

Occupational morbidity in industrial enterprises with hazardous working conditions serves as a generally accepted criterion of the negative effect of adverse production factors on human health. As can be seen from the results of the analysis, the primary occupational morbidity in the region is extremely low. At the same time, in the Aktobe region, there were isolated cases of occupational diseases that have a tendency to increase. This trend could be affected by the annual decline in the number of workers employed in hazardous working conditions since the calculation is made for 10,000 workers (according to the generally accepted method of calculating occupational morbidity). At the same time, it is necessary to take into account the fact that the West Kazakhstan branch of the RSE at the National Hygiene Center for Occupation and Occupational Diseases of the Ministry of Healthcare of the Republic of Kazakhstan is located in the city of Aktobe. Its employees conduct active organizational, methodological, therapeutic, preventive, and educational activities.

In the Atyrau, West Kazakhstan and Mangystau regions, despite the annual increase in the number of people employed in hazardous working conditions, the occupational morbidity rate is close to zero. The reason for this is more likely to be the lack of organizational measures for the early detection of occupational diseases as well as the insufficient quality of periodic medical examinations. In all three regions, there are no regional occupational pathology examination rooms. Occupational therapy posts at both the regional and republican levels are temporary, which reduces activity in this direction. The existing orders of the Ministry of Healthcare of the Republic of Kazakhstan do not allow opening occupational pathology examination rooms, as according to the current standards [27], the outpatientpolyclinic unit does not provide for occupational therapy posts. In all public polyclinics, occupational therapists are employed from paid services and their functions are limited only to conducting mandatory medical examinations (on a paid basis). The same situation is observed in private clinics.

In 2016, the National Hygiene Center for Occupation and Occupational Diseases and its affiliates underwent significant staff reductions. Due to staff shortages, the West Kazakhstan branch does not have a real possibility of full-scale organizational activities throughout the region. In addition, the geographical remoteness of the center for occupational health, located in Karaganda, can be considered a serious cause of the low rates of primary occupational morbidity since only the National Hygiene Center for Occupation and Occupational Diseases can diagnose a primary occupational disease. This geographical distance leads to difficulties in workflow and to patients refusing to travel to the center for occupational pathology.

At present, legally fixed paid (at the expense of the employer) [28] periodic medical examinations are perceived by many medical institutions only as an additional source of funding. One of the unspoken clauses of contracts concluded between the employer 
and the contractor is the non-detection of occupational diseases. Therefore, the identification of the earliest signs of occupational diseases, including general morbidity, is not at the proper level.

A new problem in the detection of occupational diseases has become the low information capacity of the sanitary and epidemiological characteristics of working conditions since it is this document that serves as the basis for establishing the primary diagnosis of an occupational disease. The results of the hygienic studies presented in this document, unfortunately, do not reflect the real working conditions of workers employed in hazardous industries. In the Republic of Kazakhstan, the majority of state-owned enterprises have become private, where profit is at the forefront; the principles of medical services provided for industrial enterprises and their accountability have changed along with the procedure for implementing the sanitary inspection of industrial enterprises. The only thing that has not changed is the approaches of occupational therapists in detecting occupational diseases characterized by conservatism, which is the reason for the failure to identify an occupational disease with obvious clinical signs in many patients.

When identifying occupational diseases, one of the requirements is the annual excess of maximum permissible concentrations and levels of harmful production factors throughout the entire occupational route. However, according to the current legislation, measurements are carried out only on the basis of mandatory prior notification of the enterprise [29]. This is probably one of the reasons for "favorable" working conditions in many hazardous industries. In addition, planned laboratory measurements are carried out as part of the state order, which does not allow for systemic sanitary and hygienic monitoring, annual measurements in all workplaces, and time-weighted averages of harmful substances and physical factors. The ongoing certification of workplaces also does not reflect the real working conditions since it is held once every 5 years [30]. Accordingly, the sanitary and epidemiological characteristics do not provide these data.

Another requirement in identifying occupational diseases is a mandatory analysis of the outpatient card to check whether the patient sought medical advice for the disease being identified. However, often, especially in the medical and preventive treatment institutions subordinated to the enterprise, there is an incorrect, possibly deliberately erroneous coding of workers' chronic diseases. In addition, workers often refuse to document temporary disability to avoid losing workdays. For this reason, occupational diseases are not identified for the majority of patients; instead, they are recommended to be treated in the "risk group."

The foregoing indicates that there is a discrepancy between employment indicators, working conditions, and real occupational morbidity rates. To solve the problems of occupational morbidity in the region, it is necessary to revise the existing orders of the Ministry of Healthcare of the Republic of Kazakhstan concerning the optimization of occupational health activities in the country, namely, to decentralize the activity of the occupational health service as well as to open occupational pathology examination rooms in all regional centers and industrial areas. It also seems appropriate to redefine and reassess the role and importance of the current sanitary and epidemiological characteristics in examining and establishing the relationship between the disease and the occupation. The implementation of effective interdepartmental and intersectoral interaction of state bodies, society, workers, and citizens will contribute to reducing the risk factors for the life and health of the working contingent.

\section{Conclusions}

There is an annual increase in the number of workers employed in hazardous production in the Atyrau, West Kazakhstan, and Mangystau regions. A different picture is observed in the Aktobe region, where the number of people employed in hazardous working conditions decreased due to the decline in industrial production. At the same time, there is a positive trend in this region to identify occupational diseases. In the Atyrau, West Kazakhstan, and Mangystau regions, despite the annual increase in the number of people employed in hazardous working conditions, the occupational morbidity rate is close to zero.

The reason for the low occupational morbidity in the West Kazakhstan region can be considered the lack of organizational measures for the early detection of occupational diseases, namely, absence of regional occupational pathology examination rooms; poor quality of ongoing examinations; poor quality certification of workplaces and incomplete registration of sanitary and epidemiological characteristics of working conditions; low motivation of patients concerning examination in the center for occupational pathology; conservatism of principles and methodological approaches to the identification of occupational diseases; and their inconsistency under the current regulatory legal base.

To solve the problems of occupational morbidity in the region, it is necessary to revise the existing orders of the Ministry of Healthcare of the Republic of Kazakhstan concerning the improvement of the occupational health service, as well as the effectiveness of interdepartmental and intersectoral interaction of state bodies, society, workers, and citizens in reducing the risk factors for the life and health of the working contingent. 


\section{References}

1. Izmerov NF. The health of the working population of Russia. Occup Health Ind Ecol. 2005;11:2-8.

2. Dymochka MA, Chikinova LN, Zaparyi NS. Disablement due to occupational diseases in Russian federation in 20122016. Occup Health Ind Ecol. 2018;4:10-3. https://doi. org/10.31089/1026-9428-2018-4-10-13

3. Andreeva EE. Primary and occupational morbidity among adult population of Moscow. Occup Health Ind Ecol. 2017;1:50-3. PMid:30351664

4. Government of the Kazakhstan. On Approval of the Occupational Health and Safety Program of the Republic of Kazakhstan for 2005-2007. Kazakhstan: Government of the Kazakhstan; 2005.

5. Zarubekov TS, Amanzhol IA. Hygienic assessment of the working conditions of employees in the oil and gas industry. In: Republican Scientific-practical Conference with International Participation. Karaganda: Modern Occupational Hygiene Issues of Occupational Diseases; 2007.

6. Mamyrbayev AA. Current problems of chemical safety of urban areas in modern conditions. Med $\mathrm{J}$ West Kazakhstan. 2015; 1(45):36-41.

7. Iztleuov MK, Mamyrbayev AA, Jarkenov TA, Iztleuova GM. Assessment of Nephrotoxicity of Combined Effects of Chromium and Boron Compounds in an Experiment. Vol. 1. North Charleston, USA: Science in the Modern in Information Society VII; 2015. p. 29-32.

8. MamyrbaevAA, Dzharkenov TA, Imangazina Z, Satybaldieva UA. Mutagenic and carcinogenic actions of chromium and its compounds. Environ Health Prev Med. 2015;20(3):11-4. https:// doi.org/10.1007/s12199-015-0458-2

9. Bekmukhambetov $\mathrm{Y}$, Mamyrbayev AA, Jarkenov TA, Imangazina Z. Cancer incidence and morbidity data in Aktobe, West Kazakhstan, 2000-2010. Asian Pac J Cancer Prev. 2015;16(6):2379-83. https://doi.org/10.7314/ apjcp.2015.16.6.2379 PMid:25824768

10. Umarova G, Mamyrbayev A, Bermagambetova S, Baspakova A, Satybaldieva U, Sabyrakhmetova V, et al. Morbidity, disability and death rates of the population due to malignant neoplasms in Uralsk city in the republic of Kazakhstan. Morb Disabil Death Rates Popul Due Malignant Neoplasms. 2016;17(12):6059-64.

11. Committee on Statistics Ministry of National Economy of Republic of Kazakhstan Available from: http://www.stat.gov.kz. [Last accessed on 2019 Apr 8].

12. Uzbekov VA, Mamyrbayev AA, Otarov EZ, Ibrayev SA, Perepichko NZ. Assessment of risk of exposure to human of the chromium compounds during chromium ore mining and ferrochromium gaining. Med Ecol. 2014;1(70):46-52.

13. Shlyapnikov DM, Shur PZ, Alekseev VB, Vlasova EM, Kostarev VG, Safonov MA. Hygienic features of working conditions and their impact on the health of workers employed in ferrovanadium production. Occup Health Ind Ecol. 2013;11:12-6.

14. Musina AA, Suleimenova RK, Kosherova PA. Functional state of the respiratory system in the working risk groups of ferrochromic production. In: New Tasks of Modern Medicine: Proceedings of the III International Scientific Conference. St. Petersburg: Zanevskaya Square; 2014.

15. Gimaeva ZF, Bakirov AB, Karimova LK, Gimranova GG, Mukhammadieva GF, Karimov DO. Production and genetic risk factors for cardiovascular diseases in petrochemical workers. Ter Arch. 2018;90(1):49-53.

PMid:30701758

16. Kenessariev UI, Zinulin UZ, Yerzhanova AE, Amrin MK Aybasova ZA. Monitoring of public health in the kashagan oil and gas field. Gig Sanit. 2016;95(8):729-33. https://doi. org/10.18821/0016-9900-2016-95-8-729-733 PMid:29430896

17. Kenessaryiev UI, Yerzhanova AE, Kenessary DU, Kenessary AU. Trends of change in demographic indices of population in the area of oil and gas deposits of the republic of Kazakhstan. Gig Sanit. 2016;95(10):946-9. https://doi. org/10.18821/0016-9900-2016-95-10-946-949 PMid:29431340

18. Mukhametzhanova SE. The issues of workers' health protection in Kazakhstan. In: Medical Ecology: Current State, Problems and Prospects. Karaganda: Proceedings of the International scientific-practical Conference Dedicated to the $20^{\text {th }}$ Anniversary of the Independence of the Republic of Kazakhstan; 2011. p. 220-3.

19. Amanbekov UA, Sakiev KZ, Amanbekova AU, Ibraeva LK Otarbaeva MB, Dzhakupbekova GM. Contemporary aspects of examination concerning relationship of disease with occupation in Kazakhstan. Occup Health Ind Ecol. 2017;5:15-8.

20. Pankov VA, Lakhman OL, Perezhogin AN, Tyutkina GA, Kuleshova MV, Smirnova OV. The dynamics of the occupational morbidity rate in the Eastern Siberia. Gig Sanit. 2016;95(12):11715. https://doi.org/10.18821/0016-9900-2016-95-12-1171-1175 PMid:29446572

21. Efimova NV, Rukavishnikov VS. Working conditions and morbidity of the working population in the Siberian Federal Okrug. Occup Health Ind Ecol. 2017;10:1-5.

22. Osipov SA, Malysheva IY, Berkheeva ZM, Trofimova MV, Giniatova AM, Safina KR. Working conditions and occupational morbidity in agricultural workers of the republic of Tatarstan. Bull Contemp Clin Med. 2016;9(5):29-34.

23. Honkonen $\mathrm{T}$, Virtanen $\mathrm{M}$, Ahola $\mathrm{K}$, Kivimäki M. Employment status, mental disorders and service use in the working age population. Scand J Work Environ Health. 2007;33(1):12-9. https://doi.org/10.5271/sjweh.1061

24. Virtanen M, Koskinen S, Kivimäki M, Honkonen T, Vahtera J, Ahola $\mathrm{K}$, et al. Contribution of non-work and work-related risk factors to the association between income and mental disorders in a working population: The health 2000 study. Occup Environ Med. 2008;65(3):171-8. https://doi.org/10.1136/ oem.2007.033159

PMid: 18283127

25. Bustos CT, Lomakin FM. Dermatitis, un enfoque desde la medicina ocupacional. Práct Clín. 2013;13(3):5645-701. https:// doi.org/10.5867/medwave.2013.03.5645

26. Decree of the President of the Republic of Kazakhstan. No. 874. On Approval of the State Program for Industrial-innovative Development of the Republic of Kazakhstan for 2015-2019. Kazakhstan: Decree of the President of the Republic of Kazakhstan; 2014.

27. Order of the Ministry of Healthcare of the Republic of Kazakhstan No. 238. On Approval of Model Personnel and State Standards of Health Organizations. Kazakhstan: Order of the Ministry of Healthcare of the Republic of Kazakhstan; 2010.

28. Code of the Republic of Kazakhstan No. 193-IV. On Public Health and Healthcare System. Kazakhstan: Code of the Republic of Kazakhstan; 2009.

29. Code of the Republic of Kazakhstan No. 375-V. Law of Entrepreneurial Code of the Republic of Kazakhstan. Kazakhstan: Code of the Republic of Kazakhstan; 2015.

30. Order of the Minister of Healthcare and Social Development of the Republic of Kazakhstan No. 1057. On Approval of the Rules for Mandatory Periodic Certification of Production Facilities for Working Conditions. Kazakhstan: Order of the Minister of Healthcare and Social Development of the Republic of Kazakhstan; 2015. 